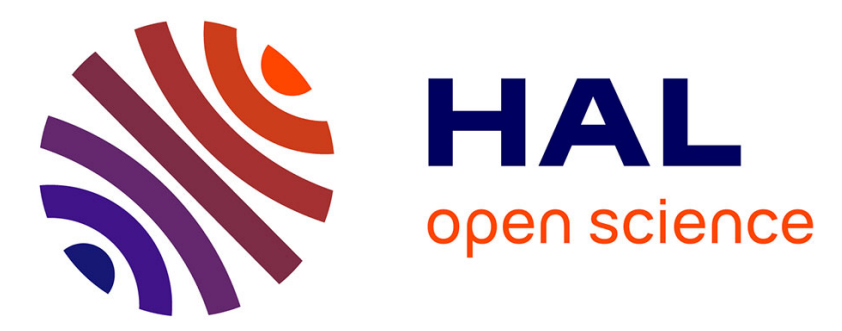

\title{
Distributed Fiber Optic Sensors for multiple crack monitoring in reinforced concrete structures
}

Antoine Bassil, Ernst Niederleithinger, Xin Wang, Daniel Kadoke, Xavier

Chapeleau, Dominique Leduc, Odile Abraham, Mathias Breithaupt, Samuel

Potschke

\section{To cite this version:}

Antoine Bassil, Ernst Niederleithinger, Xin Wang, Daniel Kadoke, Xavier Chapeleau, et al.. Distributed Fiber Optic Sensors for multiple crack monitoring in reinforced concrete structures. IWSHM 2019 - 12th International Workshop on Structural Health Monitoring, Sep 2019, Stanford, United States. pp.1-10, 10.12783/shm2019/32133 . hal-02402743v2

\section{HAL Id: hal-02402743 \\ https://hal.science/hal-02402743v2}

Submitted on 15 Dec 2019

HAL is a multi-disciplinary open access archive for the deposit and dissemination of scientific research documents, whether they are published or not. The documents may come from teaching and research institutions in France or abroad, or from public or private research centers.
L'archive ouverte pluridisciplinaire HAL, est destinée au dépôt et à la diffusion de documents scientifiques de niveau recherche, publiés ou non, émanant des établissements d'enseignement et de recherche français ou étrangers, des laboratoires publics ou privés. 
Title: Distributed Fiber Optic Sensors for multiple crack monitoring in reinforced concrete structures.

\author{
Authors : Antoine Bassil \\ Ernst Niederleithinger \\ Xin Wang \\ Daniel Kadoke \\ Xavier Chapeleau \\ Dominique Leduc \\ Odile Abraham \\ Mathias Breithaupt \\ Samuel Potschke
}

12th International Workshop on Structural Health Monitoring, IWSHM

10-12/09/2019, Stanford, California, United-States 


\begin{abstract}
In this paper, a multiple cracks monitoring system composed of a fiber optics cable and an interrogation unit based on Optical Backscattering Reflectometry technique is demonstrated. A mechanical strain transfer model is validated by performing an experimental test on a real scale reinforced concrete beam. The model is fitted to the strain spatial distributions, and the resulting parameters are discussed. Estimated crack openings are compared to those measured using traditional LVDT sensors and Digital Image Correlation (DIC) technique. Results show that this system, initially a strain monitoring system, can efficiently detect all multiple cracks, follow its propagation inside the structure, and more importantly monitor the surface and in-depth crack openings. The proposed multiple crack monitoring system will be of great help for early crack detection, as well as monitoring long-term degradation phenomenon like fatigue.
\end{abstract}

\title{
INTRODUCTION
}

Nowadays, reinforced concrete is the most employed material in the construction industry, but the global trend is to reduce its consumption rate and thus to change the focus from design of new structures to maintenance of the current constructions. The recent tragedy of Morandi Bridge collapse in Genoa has put the spotlight on the importance of health monitoring of civil infrastructures before performing repairing and maintenance works. Most of the local damage in a structure is revealed by cracks. Thus, monitoring cracks at the micro level are important to give assurances of a structures strength and serviceability.

While for a long period of time, visual inspection was commonly used to monitor cracks, a new Non-Destructive Testing technique called Digital Image Correlation (DIC) has shown its capability of crack identification (detection, localization, quantification) on

Antoine Bassil, Xavier Chapeleau, IFSTTAR, COSYS-SII, Route de Bouaye, F-44344, Bouguenais, France - Inria, Team I4S, Campus de Beaulieu, F-35042 Rennes, France. Email: antoine.bassil@ifsttar.fr Ernst Niederleithinger, Xin Wang, Daniel Kadoke, Mathias Breithaupt, Samuel Potschke, Bundesanstalt fr Materialforschung und-prfung (BAM), Unter den Eichen 87, 12205 Berlin, Germany. Dominique Leduc, GeM UMR 6183, University of Nantes, Nantes, France.

Odile Abraham, IFSTTAR, GERS-GeoEND, Route de Bouaye, F-44344 Bouguenais, France. 
the surface of the structures.

On the other hand, Distributed Fiber Optics Sensing (DFOS) techniques proved that it can achieve accurate and reliable strain measurements, while also following crack propagation (1) continuously, (2) inside and on the surface of the structure and (3) all over its length. DFOS measurement systems are composed of an interrogator and an optical fiber playing the role of a sensor. These fibers are small, resistant to corrosion and insensitive to external electromagnetic perturbations. Different interrogation units are available nowadays based on the analysis of the Brillouin and Rayleigh backscattered light all over the silica optical fiber. While it is now well established that these systems have the ability to perform accurate strain measurements and detect the presence of cracks [1-4], the possibility to quantify the crack openings through the distributed strain measurements has been recently studied [5-10].

However, all these studies consider a single crack. In a real concrete structure, multiple cracks are likely to occur resulting in a complex measured deformation with possible overlap between adjacent cracks. This paper focuses on this more realistic case where multiple close micro-cracks appear in a real scale reinforced concrete beam. The crack openings propagation on the surface of the beam as well as in-depth variations will be studied and compared to those estimated by DIC technique and measured by classical LVDT sensors.

\section{EXPERIMENTAL INVESTIGATION}

\section{Test set-up}

A 200x400x2900 mm reinforced concrete beam is tested under four-points loading. Figure 1a shows the geometrical dimensions of the beam and the position of different rebars.

(a) Reinforcement

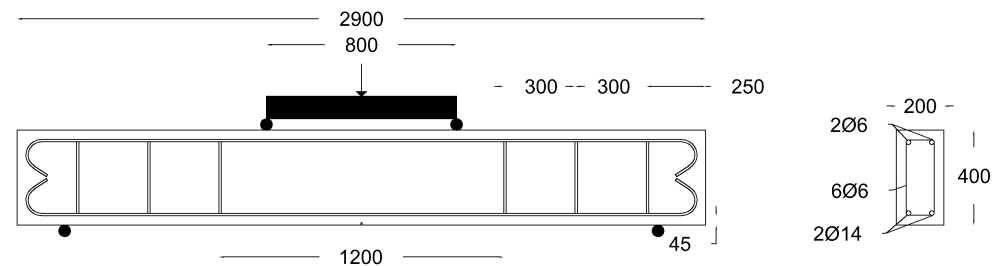

(b)

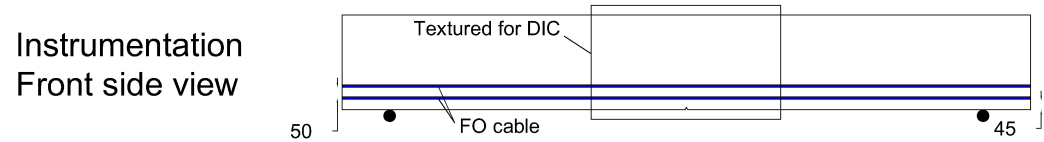

(c)

Instrumentation
Back side view

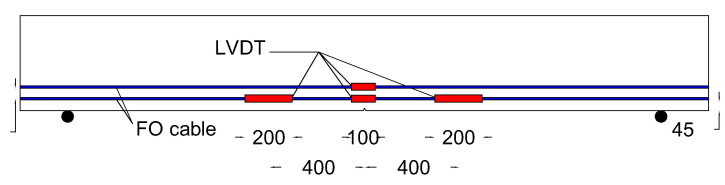

(d)
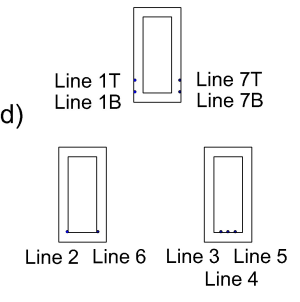

Figure 1: (a) Dimensions of the beam and different rebars positions (b) Front view with DIC textured surface position (c) Back view with LVDT sensors positions (d) Section view of different fiber optic lines positions. 
The distance between the two supports and the two loading points are respectively $2500 \mathrm{~mm}$ and $800 \mathrm{~mm}$. On the front side, the beam was textured for DIC in the area between the two loading points (Figure 1b). On the back side, two LVDT sensors where fixed on the left and right side of two other LVDT sensors fixed in the center of the beam at a top and bottom levels, respectively $45 \mathrm{~mm}$ and $95 \mathrm{~mm}$ from the bottom of the beam (Figure 1c).

One optical cable was fixed over the length of the beam at the top and bottom levels (Figure 1d). While five FO lines (FO Line 2, 3, 4, 5, 6) were embedded inside the beam before casting of concrete (Figure 2a), four other lines (FO Line 1B, 1T, 7B, 7T) were mounted on the front and back surface by gluing the optical cable inside a $3 \times 3 \mathrm{~mm}$ groove using a two-component epoxy adhesive. Figure $2 \mathrm{~b}$ shows the AFL optical cable (from Sensornet, Hertfordshire, United Kingdom) used as a sensor. The cable holds six fibers wrapped around a central rod and embedded in a soft polymer matrix (Figure 2c). One of the optical fibers was connected to the OBR 4600 interrogator (manufactured by Luna, Blacksburg, VA, United States) used for performing the measurements. Based on Optical Backscattering Reflectometry (OBR) technique, the strain measurements were calculated with a spatial resolution of $10 \mathrm{~mm}$ and a strain accuracy of $\pm 4.1 \mu \mathrm{m} / \mathrm{m}$.

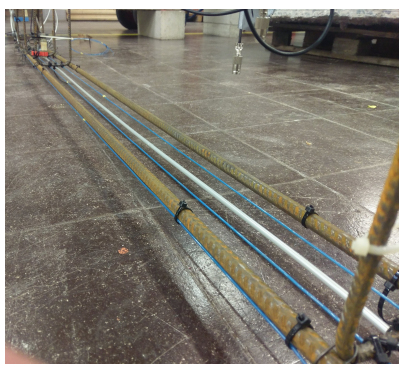

(a)

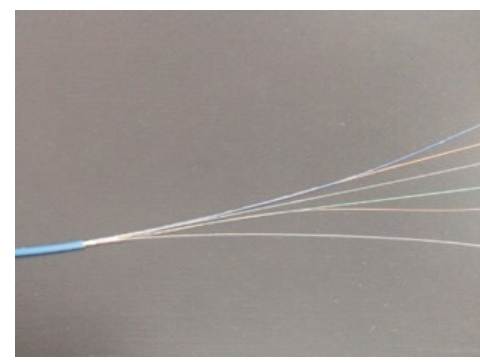

(b)

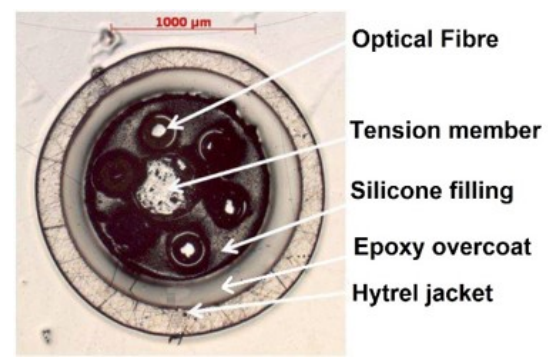

(c)

Figure 2: (a) Embedded optical fiber lines before concrete casting. (b) Photo of the optical cable [10]. (c) Micrography of different constitutive layers of the optical cable [11].

The DIC technique is based on the observation of a light-dark pattern (applied to the surface of the beam) by two synchronously triggered cameras (DIC sensor). The image of the pattern is divided into sub-image areas (so-called facets). These facets and their movement, due to the applied load, are identified and followed using the images taken during the test. Since the cameras are calibrated photogrammetrically in a stereo arrangement, the 3D coordinates of the corresponding material areas can be determined from the image positions of the facets, which lead to calculating vertical and horizontal displacement and deformation parameters. Facet size of $15 \times 15 \mathrm{~mm}$ has been fixed for this experiment. Due to the limited measurement frequency of the interrogator $(0.25 \mathrm{~Hz})$, a step-wise loading was performed until reaching an applied load of $80 \mathrm{kN}$. Between the total 64 loading steps, the first 4 steps had an amplitude of $5 \mathrm{kN}$ each, while the following 60 steps had an amplitude of $1 \mathrm{kN}$. At each step, the spatial strain distribution along the optical cable was measured using the OBR4600 interrogator and an image was taken using the two cameras. 


\section{MECHANICAL STRAIN TRANSFER FUNCTION}

Optical fibers are usually surrounded by protective layers or adhesives. It was found that a crack formation, leading to a deformation discontinuity, is sensed by the optical fiber through the intermediate layers due to strain transferring mechanisms. As a result, localized strain distribution, covering an important length (several centimeters) of the optical cable, can be measured [11]. Thus, as shown in Figure 3, direct damage detection and localization can be achieved contrary to short gauge and long gauge sensors where sophisticated algorithms are required [12]. The host material discontinuities are

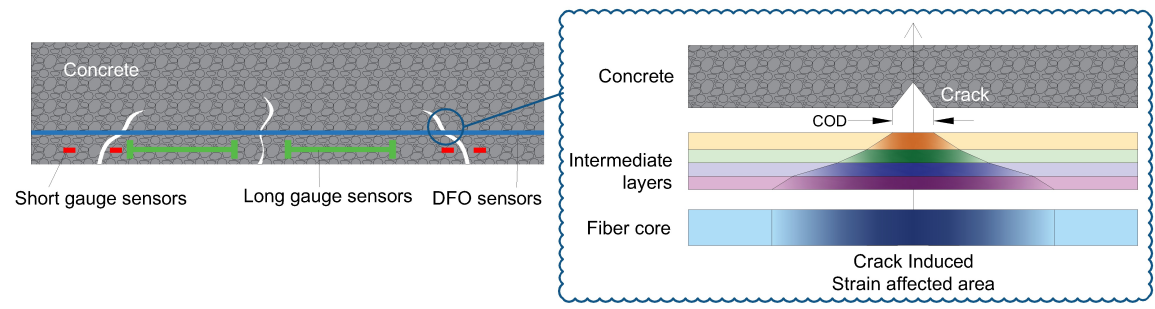

Figure 3: Crack detection using Distributed Fiber Optics Sensing (DFOS) techniques [10].

sensed by the optical fiber as localized strain distributions. The influence of the mechanical properties of different intermediate layers can be described through strain transfer theories. Several mechanical models were proposed for embedded and surface attached optical sensors directly relevant to embedded short-length sensors where the stress transferring problem at borders cannot be neglected in comparison to its high accuracy.

Feng et Al [13] established a shear lag model based on the one proposed by Ansari et Libo [14]. By assuming that the deformation discontinuity leads only to strain variations localized in the vicinity of the crack location and neglecting any effects on the axial strain or any debonding at interfaces, the authors introduced the crack opening parameter in the strain transfer analysis of a multilayered system. This system is composed of an optical fiber, intermediate layers and the host material. All different layers are assumed to have a linear elastic behavior and a perfect bonding at different interfaces. The model proposes a relationship between the strain measured by the fiber, $\epsilon_{f}(x)$, the strain in the host medium in the absence of a crack, $\epsilon_{m}(x)$, and the strain induced by the crack, via the following strain transfer equation:

$$
\epsilon_{f}(x)=\epsilon_{m}(x)+\lambda \frac{C O D}{2} e^{-\lambda|x|}
$$

Where $C O D$ and $\lambda$ represent respectively the crack opening displacement and the shear lag parameter. This equation results from assuming that $e^{2 \lambda L_{F}} \gg \frac{C O D}{2}$ and fixing the two boundary conditions: (1) $u_{f}(0)=0$ and (2) $\epsilon_{f}\left(L_{F}\right)=\epsilon_{m}$, with $u_{f}$ being the displacement in the fiber and $L_{F}$ the far field distance. As can be seen, the measured strain at the level of the optical fiber is equal to the strain in the host material added to the crack signature or crack induced strain part under the form of an exponential distribution. 


\section{RESULTS AND DISCUSSION}

Based on visual observations at full cracking state, a crack map of the beam is created by means of manual crack mapping. At the end of the test, fourteen cracks propagated inside the beam where seven are located in the DIC region between the two loading points as shown in Figure 4. The mechanical transfer function mentioned in equation 1
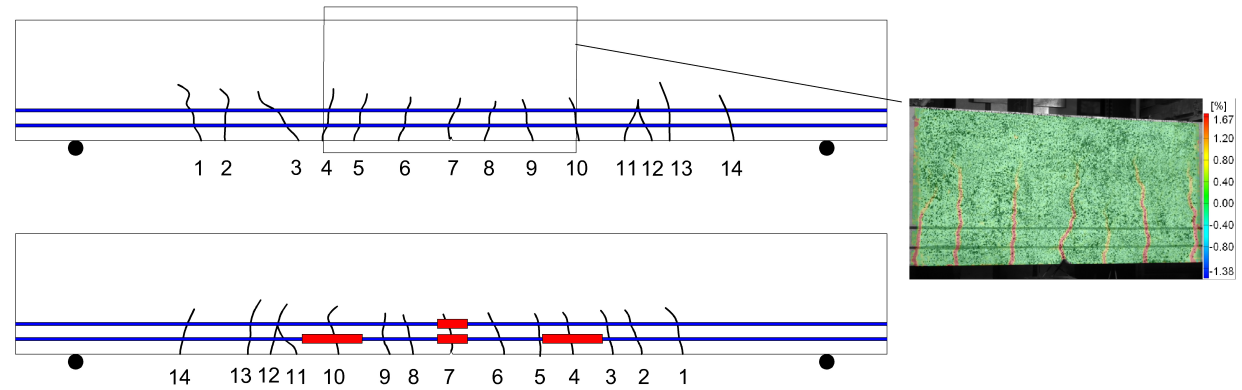

Figure 4: A cracks map of the beam's front and back side by means of manual crack mapping (left) and in the central area using DIC technique (right).

is introduced in order to fit the measured strain profiles using the least square method as follows:

$$
\epsilon_{f}(x)=\epsilon_{m}(x)+\sum_{i=1}^{k} \lambda \frac{C O D_{i}}{2} e^{-\lambda\left|x-x_{i}\right|}
$$

$C O D_{i}$ (for each crack $i$ ) and $\lambda$ are selected as variable parameters, while a trapezoidal approximation of $\epsilon_{m}(x)$ is adapted based on the strain level before the appearance of the multiple microcracks. The parameters $k$ and $x_{i}$, representing respectively the total number of cracks and their position, are fixed manually for each load step to simplify the fitting process. Figure 5 shows that the computed strain profiles are clearly in accordance with those measured by the DFOS system at each load level while low residual levels are randomly scattered around the zero line, indicating that the model describes well the measured strain data.

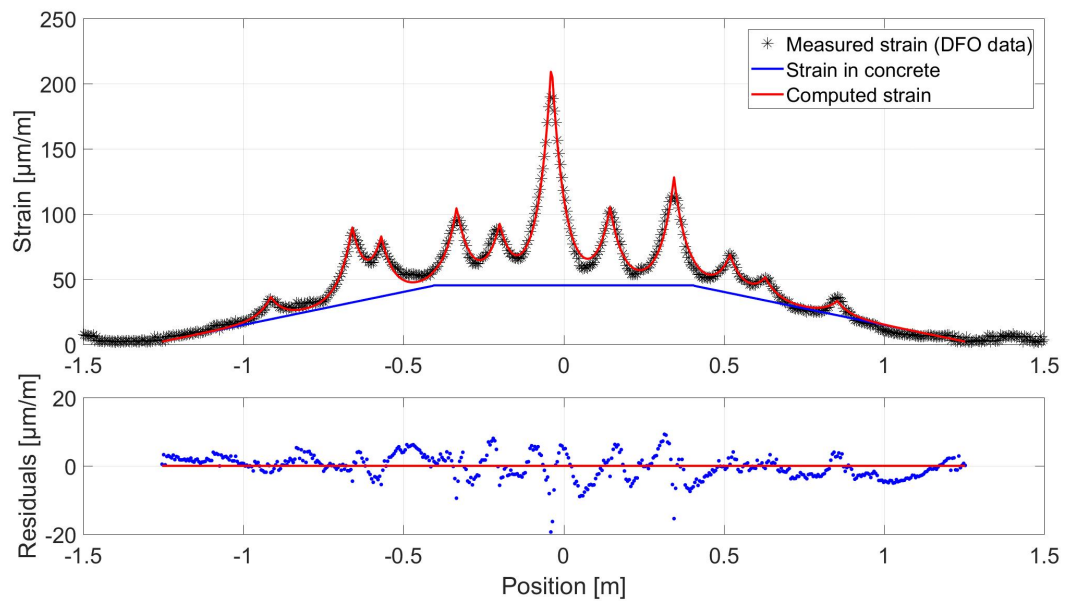

Figure 5: Computed strain spatial distribution using the strain transfer function compared to FO Line7T measured profiles at Load $=26 \mathrm{kN}$. 
On the back side of the beam, the openings of cracks 4,7 and 10 are extracted and compared to LVDT measurements. Figure 6 shows the openings of cracks 4 and 10 at the bottom level (FO Line 7B) and the opening displacement of crack 7 at the top level (FO Line 7T) as a function of the applied load. The measured openings for crack 7 at the bottom level are not presented due to a problem with the LVDT sensor glued at this crack position during the beam test.
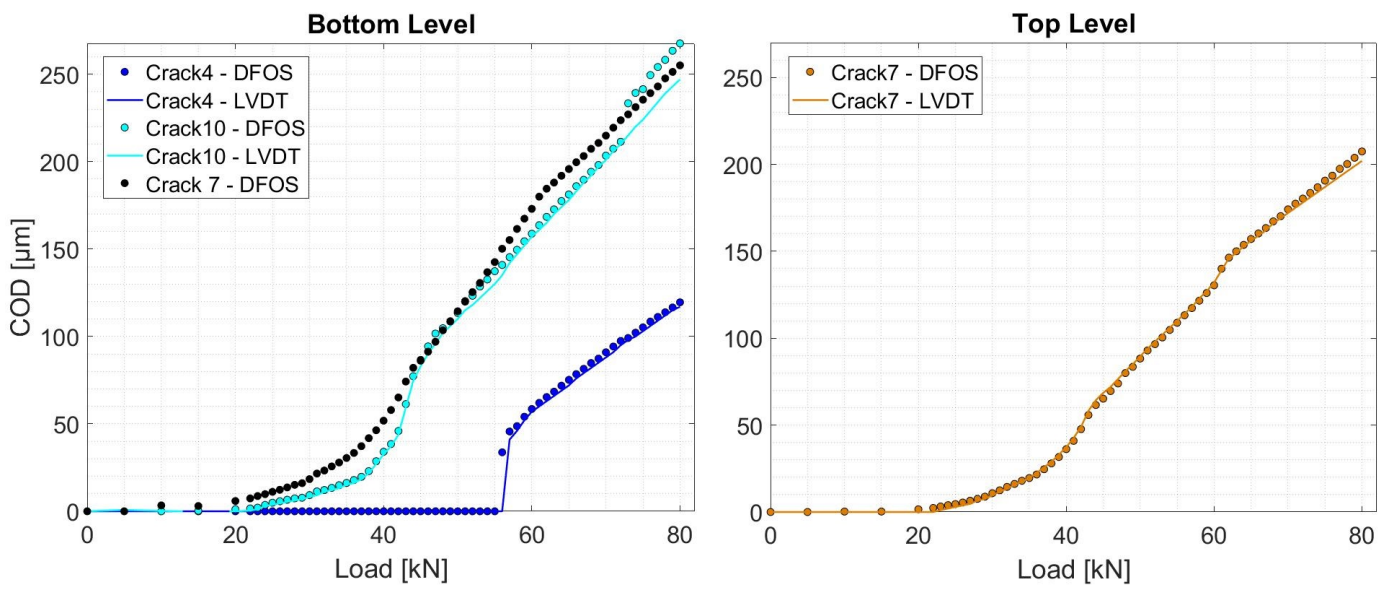

Figure 6: Variation of the estimated COD from LVDT and DFOS techniques for cracks $(4,7,10)$ at the Bottom (FO Line 7B) and Top (FO Line7T) levels.

It is clear that the estimated crack opening displacement values from the DFOS strain measurements are in accordance with those measured from LVDT sensors. These values reach the precision and repeatability level of LVDT sensors with relative difference lower than 5\%. Figure 7 shows the estimated openings for cracks (4 to 10) at the bottom (FO Line 1B) and top level (FO Line 1T). There is again an agreement between the values measured by DFOS and DIC techniques, particularly with regard to the shape of the curves. However, relative differences reached $20 \%$ for some cracks.
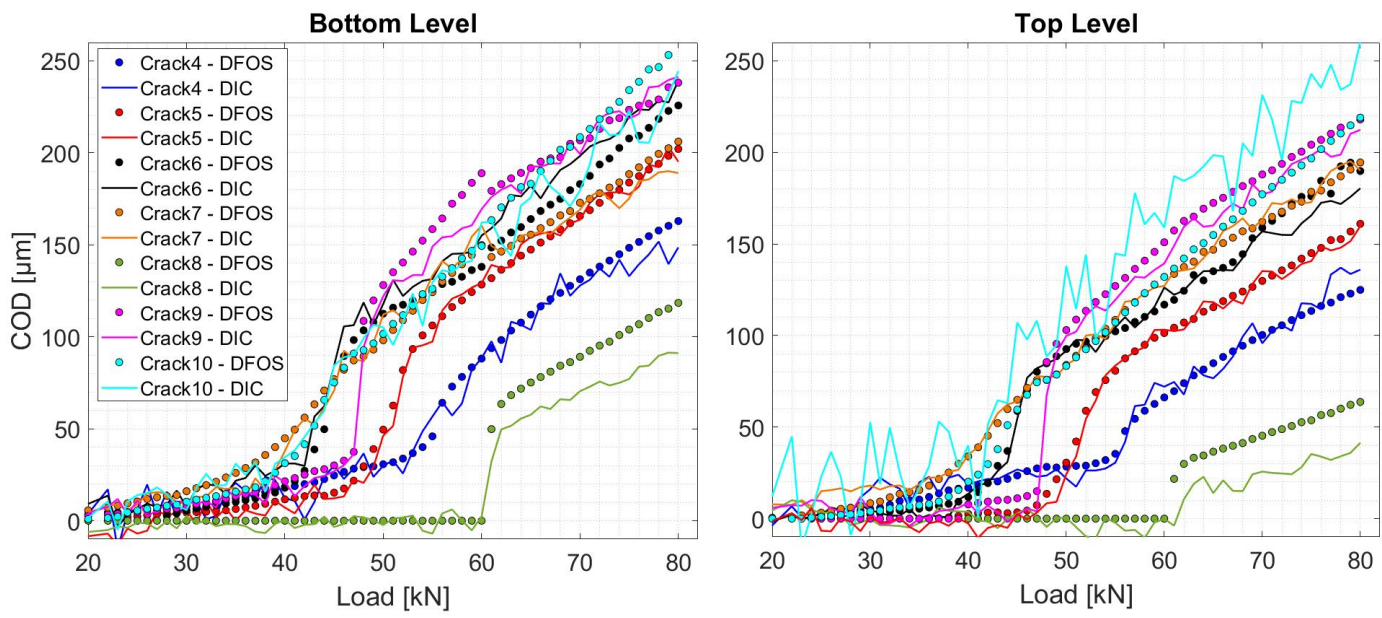

Figure 7: Variation of the estimated COD from DIC and DFOS techniques for cracks (4 to 10) at the Bottom (FO Line1B) and Top (FO Line1T) levels. 
At the top level, the estimated openings for crack 10 have higher relative error values due to its position at the border of the DIC textured surface. Another exception is crack 8 openings estimations where relative error values are inconsistent with the majority of the results. This can be attributed to the harsh crack propagation that could be the reason behind debonding initiation next to the crack location.

Due to the difficulty in finding crack meters that can be embedded inside the concrete material and are small enough to be accurate in term of position, it is hard to validate cracks openings estimations from FO Line $(2,3,5,6)$. However, by assuming a linear opening variation based on the front and back side DFOS estimations, it is possible to calculate a theoretical crack opening values at each FO line position over the thickness of the beam. As shown in Figure 8, the estimated values from FO Lines $(2,3,5,6)$ for crack 10 , where front and back side opening estimations were previously validated, are in accordance with the theoretical values with a relative error varying around $\pm 10 \%$.

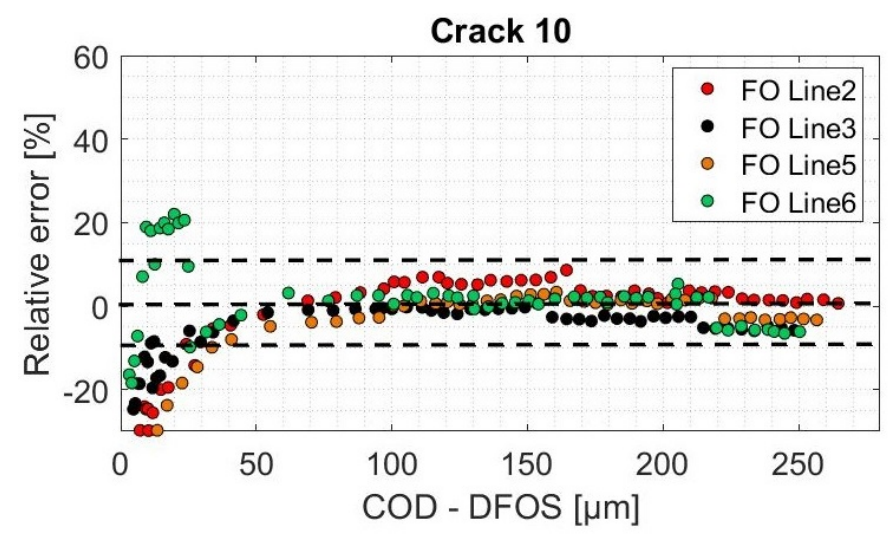

Figure 8: Relative error between estimated COD values from FO Lines $(2,3,5,6)$ and theoretical values based on the simple linear variation assumption crack 10.

\section{CONCLUDING REMARKS}

In this paper, the capacity of a Rayleigh based DFOS system to perform multiple crack identification in a reinforced concrete beam has been examined. DFOS strain measurements allowed early crack detection and localization during the linear elastic state of the reinforced concrete beam. By fitting the strain-transferring model to the DFOS strain measurements, the crack opening displacement values for each of the multiple microcracks were estimated. DFOS technique achieved similar accuracy as LVDT sensors and DIC techniques. Moreover, DFOS technique shows better repeatability than DIC technique. By assuming linear crack openings variation over the thickness of the beam, the strain measurements from embedded optical fiber lines inside the beam show similar results.

Based on these results, one can imagine a structural health monitoring system based on the implemented DFOS system. In addition to the possibility to monitor strain over the length of the structure with a good accuracy almost equal to strain gauge sensors, the spatial strain measurements from this DFOS system can be used to accurately detect and localize all the microcracks at early stages and estimate the crack openings. As a 
conclusion, this strain monitoring system can also function as a multiple cracks opening monitoring system. The novelty of this SHM system could be in its capacity to monitor continuously the full length of a medium size civil infrastructure, like a bridge, by providing not only on the surface but also in-depth crack openings. Establishing this crack monitoring technique opens the road for studying long term phenomena like the fatigue of reinforced concrete structures or new materials like ultra high-performance fiber reinforced concrete. As a next step, the durability of the system should be examined by studying the behavior of the optical cable under mechanical and environmental cyclic loading.

\section{ACKNOWLEDGEMENTS}

This research has been performed within the framework of the project INFRASTAR (infrastar.eu) which has received funding from the European Unions Horizon 2020 research and innovation program under the Marie SkodowskaCurie grant agreement No 676139. The grant is gratefully acknowledged. The support of Lange Marco, Smith Sean and Gutheins Nico from BAM in preparing the tested beam is deeply acknowledged.

\section{REFERENCES}

1. Henault, J.-M., M. Quiertant, S. Delepine-Lesoille, J. Salin, G. Moreau, F. Taillade, and K. Benzarti. 2012. "Quantitative strain measurement and crack detection in RC structures using a truly distributed fiber optic sensing system," Construction and Building Materials, 37:916-923, doi:http://dx.doi.org/10.1016/j.conbuildmat.2012.05.029.

2. Buchoud, E., J.-M. Henault, G. D'Urso, A. Girard, S. Blairon, J. I. Mars, and V. Vrabie. 2012. "Development of an Automatic Algorithm to Analyze the Cracks Evolution in a Reinforced Concrete Structure from Strain Measurements Performed by an Optical Backscatter Reflectometer," in $4^{\text {th }}$ Workshop on Civil Structural Health Monitoring, Berlin, Germany, p. P10.

3. Villalba, S. and J. R. Casas. 2013. "Application of optical fiber distributed sensing to health monitoring of concrete structures," Mechanical Systems and Signal Processing, 39(12):441451, ISSN 0888-3270, doi:10.1016/j.ymssp.2012.01.027.

4. Mirzazadeh, M. M. and M. F. Green. 2018. "Fiber Optic Sensors and Digital Image Correlation for Measuring Deformations in Reinforced Concrete Beams," Journal of Bridge Engineering, 23(3).

5. Imai, M. and M. Feng. 2012. "Sensing optical fiber installation study for crack identification using a stimulated Brillouin-based strain sensor," Structural Health Monitoring:1475921712442440, doi:http://dx.doi.org/10.1177/1475921712442440.

6. Billon, A., J.-M. Hénault, M. Quiertant, F. Taillade, A. Khadour, R.-P. Martin, and H. Benzarti, Karim. 2015. "Qualification of a distributed optical fiber sensor bonded to the surface of a concrete structure: a methodology to obtain quantitative strain measurements," Smart Materials and Structures, 24(11):115001, doi:http://dx.doi.org/10.1088/09641726/24/11/115001.

7. Meng, D. and F. Ansari. 2016. "Interference and differentiation of the neighboring surface microcracks in distributed sensing with PPP-BOTDA," Applied Optics, 55(34):9782-9790, ISSN 1539-4522, doi:10.1364/AO.55.009782. 
8. Babanajad, S. K. and F. Ansari. 2017. "Mechanistic Quantification of Microcracks from Dynamic Distributed Sensing of Strains," Journal of Engineering Mechanics:04017041.

9. Bassil, A., X. Chapeleau, D. Leduc, and O. Abraham. 2018. "Quantification of cracks in reinforced concrete structures using distributed fibre optic sensors," in EWSHM 2018, 9th European Workshop on Structural Health Monitoring Series, p. 9p.

10. Bassil, A., X. Wang, X. Chapeleau, E. Niederleithinger, O. Abraham, and D. Leduc. 2019. "Distributed fiber optics sensing and coda wave interferometry techniques for damage monitoring in concrete structures," Sensors, 19(2):356.

11. Henault, J.-M. 2013. Approche méthodologique pour l'évaluation des performances et de la durabilité des systèmes de mesure répartie de déformation: application à un câble à fibre optique noyé dans le béton, Ph.D. thesis, Université Paris-Est, henault talked about fatigue.

12. Glisic, B. and D. Inaudi. 2012. "Development of method for in-service crack detection based on distributed fiber optic sensors," Structural Health Monitoring, 11(2):161-171, doi: $10.1177 / 1475921711414233$.

13. Feng, X., J. Zhou, C. Sun, X. Zhang, and F. Ansari. 2013. "Theoretical and experimental investigations into crack detection with BOTDR-distributed fiber optic sensors," Journal of Engineering Mechanics, 139(12):1797-1807, doi: http://dx.doi.org/10.1061/(ASCE)EM.1943-7889.0000622.

14. Ansari, F. and Y. Libo. 1998. "Mechanics of bond and interface shear transfer in optical fiber sensors," Journal of engineering mechanics, 124(4):385-394. 